Article

\title{
Expression, Characterisation and Homology Modelling of a Novel Hormone-Sensitive Lipase (HSL)-Like Esterase from Glaciozyma antarctica
}

\author{
Hiryahafira Mohamad Tahir ${ }^{1,2}$, Raja Noor Zaliha Raja Abd Rahman 1,3®D, \\ Adam Thean Chor Leow ${ }^{1,4}$ and Mohd Shukuri Mohamad Ali 1,2,* \\ 1 Enzyme and Microbial Technology Research Center, Faculty of Biotechnology and Biomolecular Sciences, \\ Universiti Putra Malaysia, Serdang, Selangor 43400, Malaysia; firatahir3@gmail.com (H.M.T.); \\ rnzaliha@upm.edu.my (R.N.Z.R.A.R.); adamleow@upm.edu.my (A.T.C.L.) \\ 2 Department of Biochemistry, Faculty of Biotechnology and Biomolecular Science, Universiti Putra Malaysia, \\ Serdang Selangor 43400, Malaysia \\ 3 Department of Microbiology, Faculty of Biotechnology and Biomolecular Sciences, Universiti Putra Malaysia, \\ Serdang Selangor 43400, Malaysia \\ 4 Department of Cell and Molecular Biology, Faculty of Biotechnology and Biomolecular Sciences, \\ Universiti Putra Malaysia, Serdang Selangor 43400, Malaysia \\ * Correspondence: mshukuri@upm.edu.my; Tel.: +603-9769-6721
}

Received: 2 October 2019; Accepted: 5 November 2019; Published: 1 January 2020

check for updates

\begin{abstract}
Microorganisms, especially those that survive in extremely cold places such as Antarctica, have gained research attention since they produce a unique feature of the protein, such as being able to withstand at extreme temperature, salinity, and pressure, that make them desired for biotechnological application. Here, we report the first hormone-sensitive lipase (HSL)-like esterase from a Glaciozyma species, a psychrophilic yeast designated as GlaEst12-like esterase. In this study, the putative lipolytic enzyme was cloned, expressed in E. coli, purified, and characterised for its biochemical properties. Protein sequences analysis showed that GlaEst12 shared about 30\% sequence identity with chain A of the bacterial hormone-sensitive lipase of E40. It belongs to the $\mathrm{H}$ group since it has the conserved motifs of Histidine-Glycine-Glycine-Glycine (HGGG)and Glycine-Aspartate-Serine-Alanine-Glycine (GDSAG) at the amino acid sequences. The recombinant GlaEst12 was successfully purified via one-step Ni-Sepharose affinity chromatography. Interestingly, GlaEst12 showed unusual properties with other enzymes from psychrophilic origin since it showed an optimal temperature ranged between 50-60 ${ }^{\circ} \mathrm{C}$ and was stable at alkaline $\mathrm{pH}$ conditions. Unlike other HSL-like esterase, this esterase showed higher activity towards medium-chain ester substrates rather than shorter chain ester. The 3D structure of GlaEst12, predicted by homology modelling using Robetta software, showed a secondary structure composed of mainly $\alpha / \beta$ hydrolase fold, with the catalytic residues being found at $\operatorname{Ser}^{232}$, $\mathrm{Glu}^{341}$, and His ${ }^{371}$.
\end{abstract}

Keywords: psychrophilic yeast; hormone-sensitive lipase; Glaciozyma antarctica; Antarctica and homology modelling

\section{Introduction}

The lipolytic enzyme consists of esterases (EC 3.1.1.1) and lipases (EC 3.1.1.3) that catalyse both the cleavage and formation of ester bonds [1]. Although they have similar secondary structures, i.e., $\alpha / \beta$ hydrolase fold, esterase prefers to hydrolyse fatty-acids esters with acyl chain with less than 10 carbon atoms, whereas lipase is able to hydrolyse long-chain fatty acids with more than 10 carbon atoms [2]. Based on the sequence similarity, these protein have been classified into four groups, 
namely, C (cholinesterases and fungal lipase), L (lipoprotein and bacterial lipase), H (mammalian hormone-sensitive lipase and hormone-sensitive lipase (HSL)-like family), and $X(\alpha / \beta$ hydrolase and does not belong to any of the other groups) [3].

The $\mathrm{H}$ group consists of two members that are HSL and HSL-like, in which both of them having conserved motifs, such as GDSAG or Glycine-Threonine-Serine-Alanine-Glycine (GTSAG) and HGGG motifs. Hormone-sensitive lipase is an enzyme that is mostly found in mammalian tissue and stimulated by several hormones, such as catecholamines, $\mathrm{ACTH}$, and glucagon, to hydrolyse the triglyceride into free fatty acids and glycerol, which makes it play a pivotal role in providing the major source of energy for most tissues [4,5]. Another member of the H group is HSL-like, which is mostly originated from microbial sources that have similar protein sequences with HSL, especially at the C-terminal catalytic domain [6]. Although the mechanism of catalysis and the function of N-terminal domain HSL-like in microorganisms is still scarcely explored, the discovery of this new enzyme provides biotechnological application, such as in biosensors to detect foodborne bacteria and organophosphate pesticides $[7,8]$. Besides that, HSL-like enzymes also have potential to be used in the pharmaceutical, biodiesel, and detergents industry $[6,9,10]$.

Several HSL-like enzymes have been reported from microbial sources, such as RmEstB from the thermophilic fungus Rhizomucor miehei [11], PMGL2 from a permafrost bacterium Psychrobacter cryohalolentis [12], and E25 HSL esterase from a surface sediment sample E505 collected from the South China Sea [13]. Even though there are many reported HSL-like esterase from psychrophilic microorganisms on heterologous expression and biochemical characterisation, there are few reports on HSL-like esterase specifically from psychrophilic yeast. Discovery of the new HSL-like esterase from psychrophilic yeast not only provides an opportunity in biotechnology application but also gives crucial information on novel sequence, characterisation, and the structure-function relationship.

Glaciozyma antarctica strain PI12 is a member of the phylum Basidiomycota that was previously known as the Leucosporidium antarcticum [14]. This psychrophilic yeast was isolated from sea ice near the Casey Research Station in Antarctica and had optimum temperature growth at $12{ }^{\circ} \mathrm{C}$ but can grow at up to $18^{\circ} \mathrm{C}$ [15]. A few reported proteins have been successfully expressed from G. antarctica such as proteases, antifreeze protein, $\alpha$-amylase, and chitinase [16-19]. In this work, we report the heterologous expression, purification, biochemical characterisation, and structural prediction of the first HSL-like esterase from the Glaciozyma Antarctica species, and we also believe this enzyme is the first HSL-like esterase from psychrophilic basidiomycete yeast.

\section{Results and Discussion}

\subsection{Sequence Analysis of GlaEst12}

The amino acid sequence of Glaciozyma antarctica hormone-sensitive lipase (GlaEst12) esterase was searched for similarity against the protein data bank at the National Centre of Biotechnology (NCBI) (https://blast.ncbi.nlm.nih.gov/Blast.cgi) using BLASTP. The search results showed that GlaEst12 had low sequence similarity (about $30 \%$ identity) with chain A of the crystal structure of esterase 40 from the bacterial HSL family and apparently no homology to the HSL-like esterase from psychrophilic yeast or bacteria. No similarity of the GlaEst12 sequence with psychrophilic microorganism may have two possible explanations. Firstly, there is less discovery of this type of enzyme from a cold environment, so the possibility of this GlaEst12 sequence being similar to other mesophiles and thermophiles is quite high. Hormone-sensitive lipase from Psycrobacter sp. that has been isolated from Antarctic seawater also showed similar reports in that the enzyme is closely related to the HSL-like esterase from the mesophilic enzyme [20]. Another explanation is because GlaEst12 showed mesophilic or thermophilic characteristics rather than psychrophilic features. The limited sequence of the GlaEst12 to the known HSL-like esterase sequences indicated less conserved residues, which provide novelty properties. The nucleotide sequence of GlaEst12 revealed an open reading frame (ORF) of 1200 nucleotide, which 
encoded 399 amino acids with a predicted molecular weight of $44.5 \mathrm{kDa}$. This esterase lacks signal peptide and has a theoretical isoelectric point $(\mathrm{pI})$ value of 7.72 .

The multiple sequence alignment was performed using ENDscript with the other seven proteins that have higher percentage of sequence similarity with GlaEst12 esterase, in which they are chain A of esterase from the bacterial HSL family (PDB ID: 4XVC A); chain A of mutant S202w/203f of the Esterase E40 (PDB ID: 5GMS A); chain C of mutant M3+s202w/i203f of Esterase E40 (PDB ID: 5GMR C); chain A of esterase/lipase from uncultured bacterium (PDB ID: 3V9A A); chain A of Hormone-sensitive lipase-like Este5 (PDB ID: 3FAK A), chain A of hyper-thermophilic carboxylesterase from archaeon Archaeoglobus fulgidus (PDB ID: 1JJI A), and chain A of MGS-MT1, an alpha/beta hydrolase enzyme from a Lake Matapan deep-sea metagenome library. Surprisingly, the GlaEst12 sequence is closely related to the mesophilic and thermophilic esterase. None of them are from either a psychrophilic or Antarctica environment. This finding might give new insight into the highly similar protein sequences that are not usually from the same environment.

Multiple sequence alignment showed that GlaEst12 belongs to the $\mathrm{H}$ group of the lipolytic group, which consists of a type of protein that has sequence similarity with the HSL subfamily. Most of the members of the $\mathrm{H}$ group have two highly conserved motifs, which are also present in the GlaEst12 sequence, such as His-Gly-Gly-Gly at upstream of the catalytic triad and the residue of serine at GDSAG motif [3]. Figure 1 shows GlaEst12 adhered to the characteristic of the H group, which is indicated by the red residue for HGGG and GDSAG motifs. The alignment with other proteins showed the possibility of the catalytic residue of GlaEst12 at position $\mathrm{Ser}^{232}, \mathrm{Glu}^{341}$, and $\mathrm{His}^{371}$. The hormone-sensitive lipase-like family (HSL-like) can be widely found in microorganisms, animals, and plants. Most of the microbial HSL-like family consists of two subfamilies, GDSAG and GTSAG [21]. Since the serine residue was located at the pentapeptide motif, which is in the middle between aspartate acid and alanine, we proposed that GlaEst12 is a new member of the GDSAG subfamily of the HSL family.

Furthermore, the phylogenetic tree was constructed based on the amino acid sequence that aligned with closely related proteins and with the other members of HSL-like esterase from prokaryotic and eukaryotic microorganisms (PDB ID: 4QO5; 4Q30; 4WY8; 4WY5; Accession number: WP_012330536.1, ADH59412, QBH67630.1, KX580963.1). The results showed that GlaEst12 is grouped under the GDSAG motif subfamily (Figure 2) together with other proteins containing a GDSAG conserved sequence. Interestingly, GlaEst12 was assigned at a different sub-branch with other GDSAG subfamily members, indicating the differences of this sequence with the other esterases. The contrast may be due to the presence of extra $\alpha$-helix at the $\mathrm{N}$-terminal region, which was absent in all other esterases. Apart from that, this esterase is mostly related to eukaryotic proteins, such as RmEsTA (PDB 4WY5) and RmEsTB (PDB 4WY8), since they come from fungi species. 


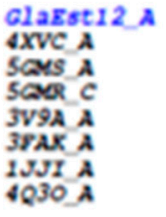

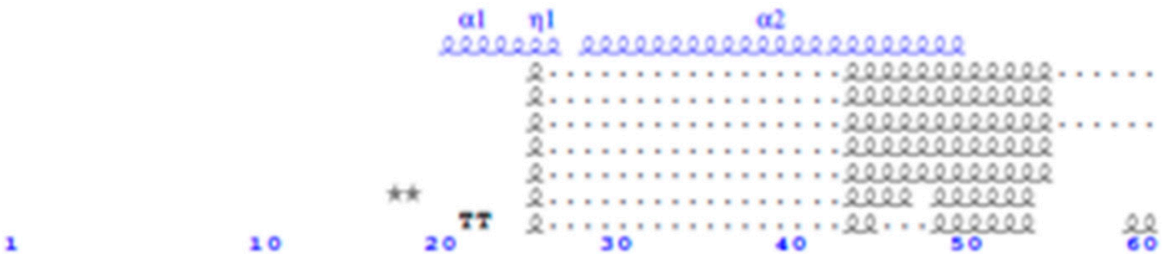

G1aEst12 a KLSPVELSK...... DKVYPRLPDTPYSSOFWKAYYIVYRLTTALALALYWALLHETPLNPYDRVW

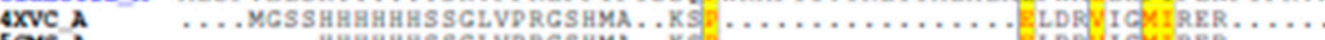

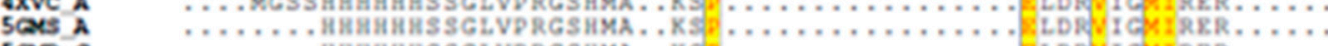
$5 \cos c$

$3 \mathrm{~V} 9 \mathrm{~A}$ a

$3 \mathrm{gax}$ A

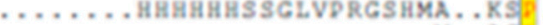

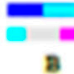

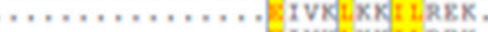
P. AGEQAKEVPIPQSiSA

MrYCLAETFOSLPX....

Glassti2 A

AXr'A

SCONSA

Sarrc

JV9A A

$1351-A$

$a$

3
$2 e c e r e$

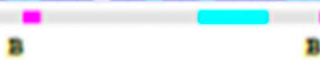

, s.

$4 Q 30$ A
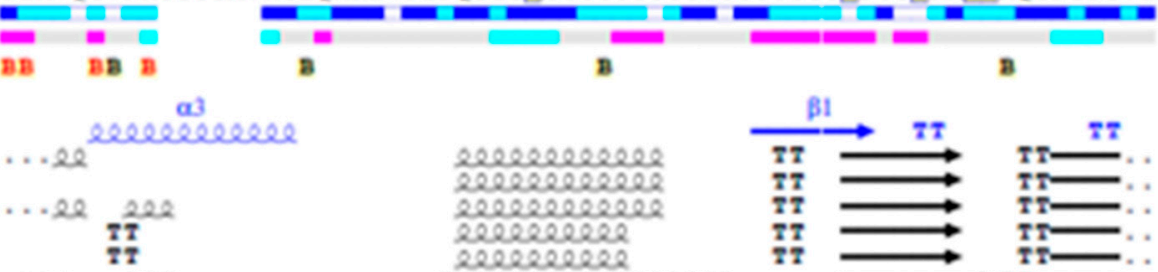

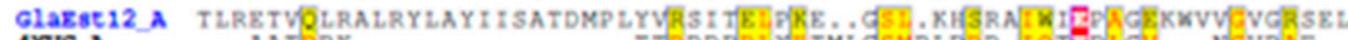

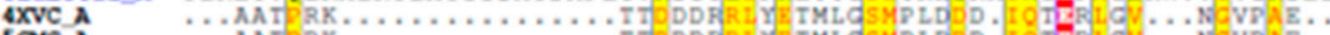

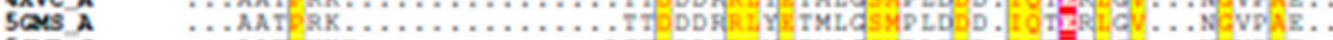

$S G Q R C$

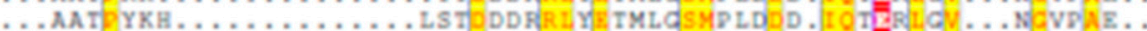

3V 9 A $A$

3 rak A

$13 \mathrm{IS}$ A

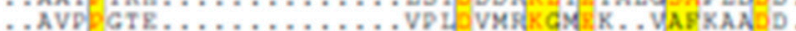

$4030 \mathrm{~A}$

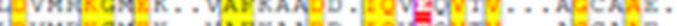

...

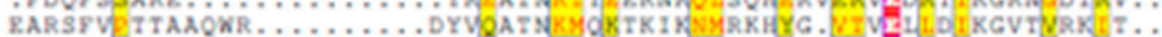

Glassti2 A
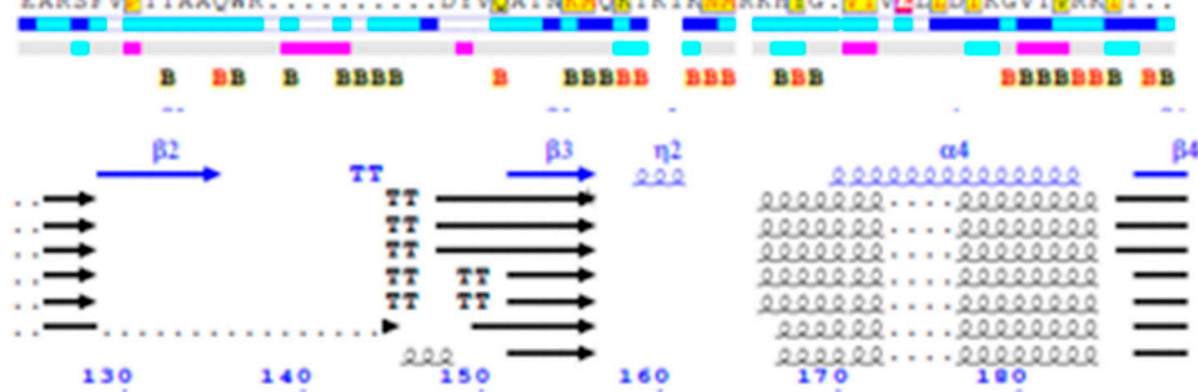

160

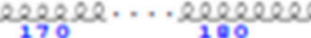

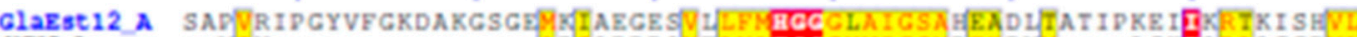

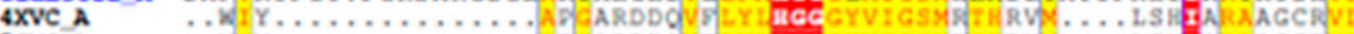

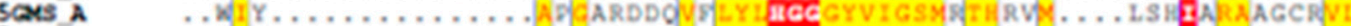

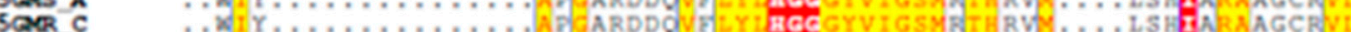

$3 \mathrm{~V} 9 \mathrm{~A}$ A

LSTERAAGCRVI

3 FaK A

1302 A

4030 A

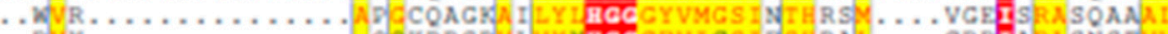

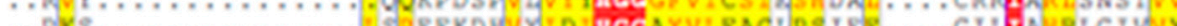
acc

Glagst2 2 A

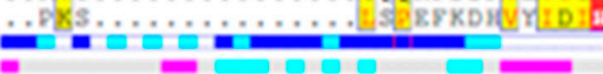

Figure 1. Cont. 

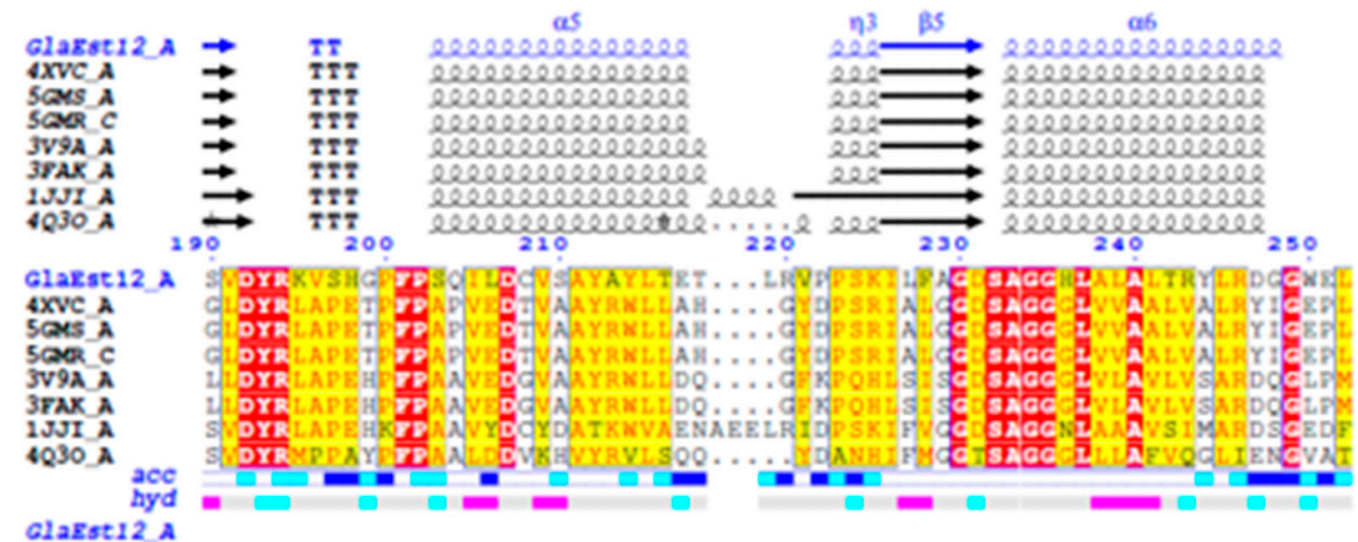

Glagst 2 A
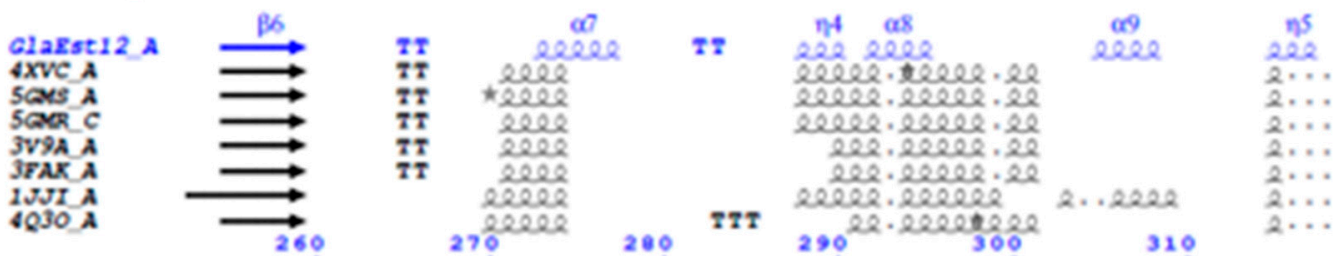

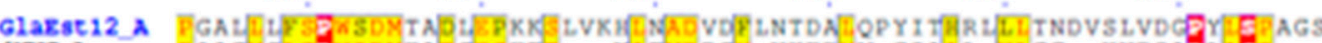

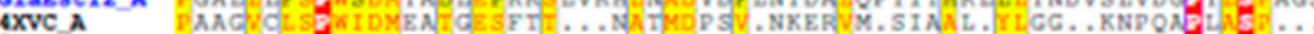

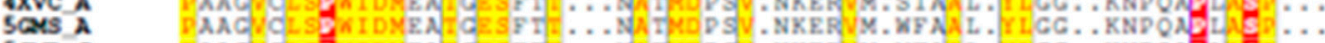

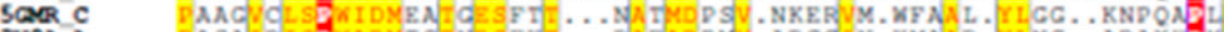
$3 V 9 A$ A

3 Y A A

$3 \sin ^{2}$

$4030 \mathrm{~A}$

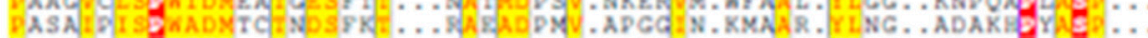

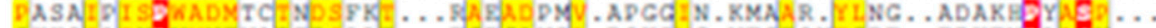

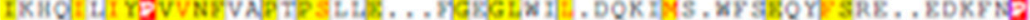
acc Glagsti2 A

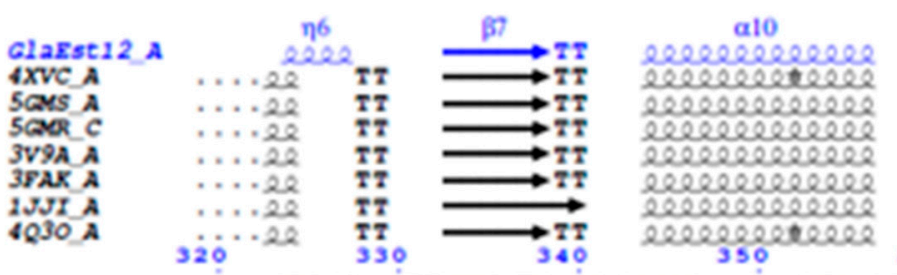

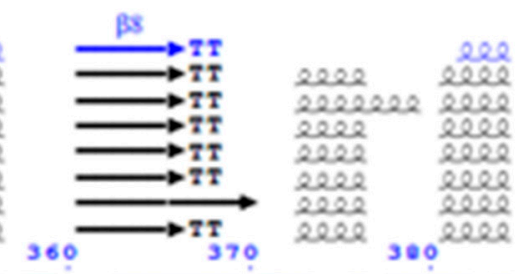

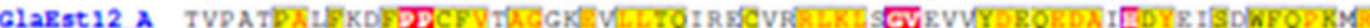

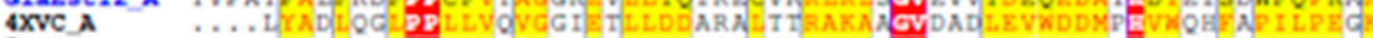

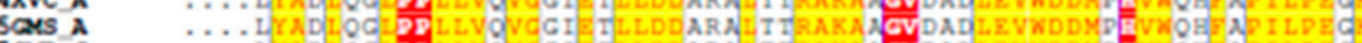

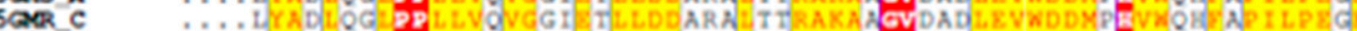
3V9A A …N.

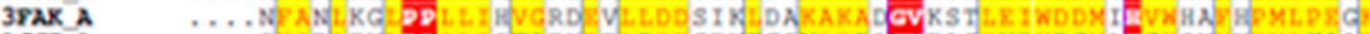

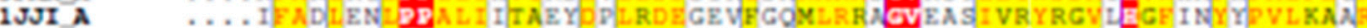

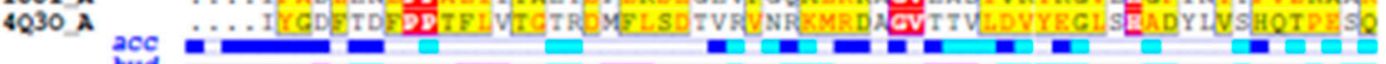
Glazst 12 A

\begin{tabular}{|c|c|}
\hline & \\
\hline Sla: & recelecere \\
\hline $4 X V$ & levereleverer \\
\hline GM & elee \\
\hline $5 G M R C$ & erevel \\
\hline & 202 \\
\hline $3 F$ & elebele \\
\hline & \\
\hline & $\begin{array}{r}\text { Cele } \\
39\end{array}$ \\
\hline la. & ERIWK TIALWV \\
\hline $4 \times \mathrm{V}$ & QAIA \\
\hline $5 \mathrm{GM}$ & QA I AR I GEF LR \\
\hline $5 \mathrm{GM}$ & QAIARIGEF LRK \\
\hline $3 \mathrm{~V} 9$ & QA IVRVGEFMREQWA \\
\hline & QA IVRVGEFMREQW. \\
\hline A & DAINOIAALIVED. \\
\hline & SVYRQLKRF LVGF: \\
\hline $\begin{array}{l}\text { ac } \\
\text { hy }\end{array}$ & $=2$ \\
\hline
\end{tabular}
GlaEst 12 A

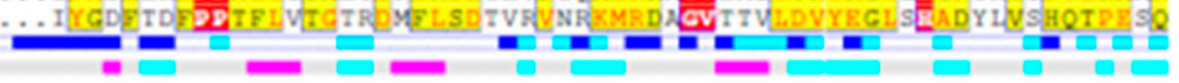

Figure 1. Multiple alignments of amino acid and secondary structure protein sequences from Glaciozyma Antarctica of hormone-sensitive lipase (GlaEst12) esterase with other related proteins. Squiggles indicate helices, arrows indicate $\beta$-strands, TT letters indicate a turn, $\eta$ letters indicate random coil and the catalytic triad are indicated by an arrow symbol. The identical and highly conserved residues are indicated by red and yellow colour, respectively. 


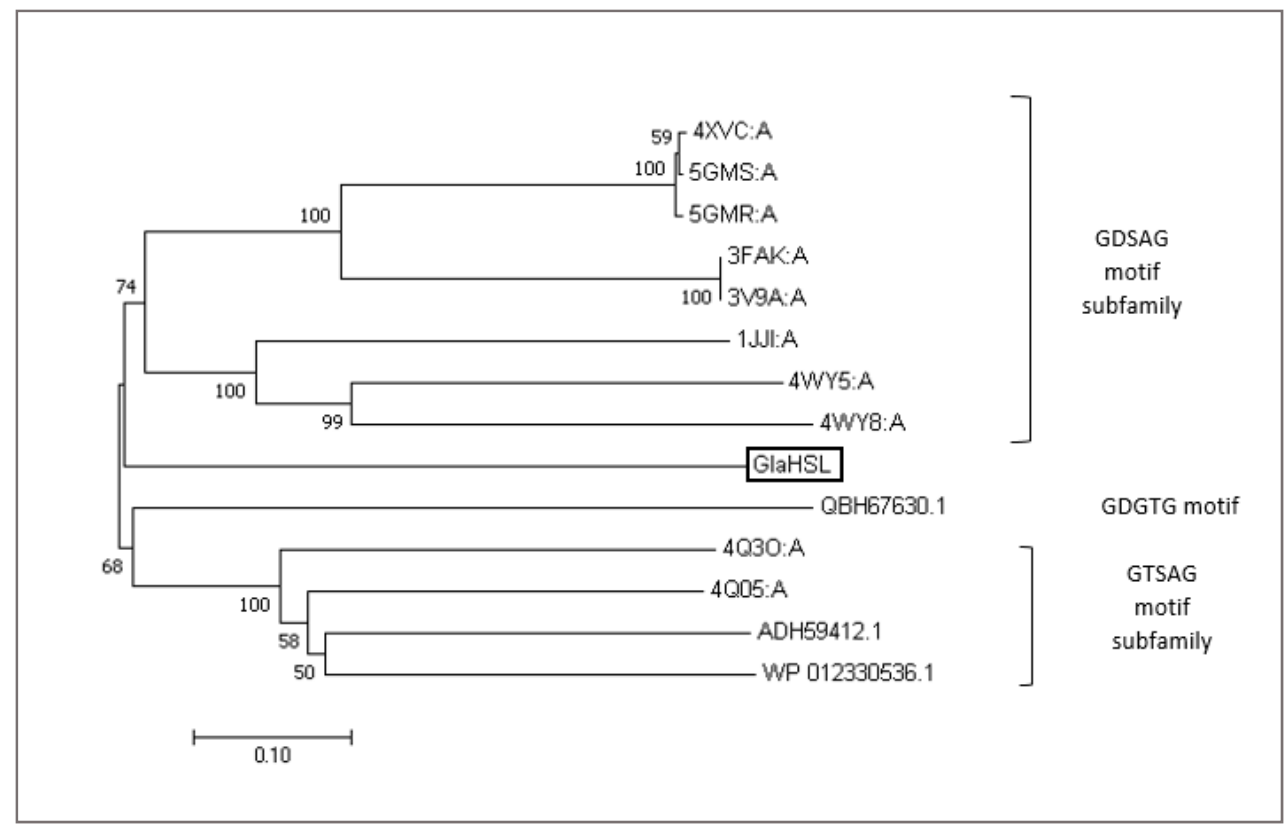

Figure 2. Phylogenetic tree of representative esterase sequences from microbial hormone-sensitive lipase (HSL) family generated using MEGA 7.0. The amino acid sequences were retrieved from the National Centre of Biotechnology (NCBI) and Research Collaboratory for Structural Bioinformatics Protein Data Bank (RCSB PDB) database. The neighbour-joining method was built with a Jones-Taylor-Thornton matrix-based model to estimate the phylogenetic tree. The black box indicates GlaEst12.

\subsection{Expression and Purification of Recombinant GlaEst12}

GlaEst12-like esterase was cloned and expressed in an E. coli BL21(De3)/pET32b(+) expression system, which resulted in the accumulation of expressed GlaEst12 in the form of inclusion bodies. It is well known that high-level expression recombinant protein in E. coli is usually formed of partially folded or misfolded protein. HSL-like esterases from Psychrobacter sp. TA144 [20] and Mycobacterium tuberculosis LIPY [22] were also expressed as inclusion bodies. In the case of recombinant GlaEst12, the active enzyme was successfully renatured (Figure 2). A protein band corresponding to GlaEst12-like esterase with an expected size of $63 \mathrm{kDa}$ was obtained as visualised by sodium dodecyl sulphate-polyacrylamide gel electrophoresis (SDS-PAGE). High expression of GlaEst12 in inclusion bodies leads to solubilisation and refolding to recover the bioactive protein. The proper protein folding of the aggregated protein in inclusion bodies was achieved by solubilising it with a high concentration of urea and then refolded by dilution. The refolded GlaEst12 esterase showed the highest esterase activity that revealed the successful solubilisation of GlaEst12 from inclusion bodies. The expression of recombinant GlaEst12 was optimised with the temperature, induction time, and isopropyl $\beta$-D-1-thiogalactopyranoside concentration at $16^{\circ} \mathrm{C}, 20 \mathrm{~h}$, and $10 \mu \mathrm{M}$, respectively.

The crude refolded GlaEst12 was purified in one-step purification using nickel sepharose affinity chromatography. N-terminal of polyhistidine (His-tag) in pET32b(+) vector was fused and expressed together with esterase, which enables the protein-containing polyhistidine to bind the specific immobilised Nickel (II) ions [23]. The crude refolded GlaEst12 was loaded into a nickel sepharose column, and the bound of protein was eluted using an ascending wise gradient of imidazole concentration. The bound protein was eluted at $300 \mathrm{mM}$ Imidazole concentration and was checked for the presence of target protein by performing a lipase assay and SDS-PAGE. Figure 3 shows a single band on SDS-PAGE with a molecular weight of $63 \mathrm{kDa}$, which is consistent with the size of GlaEst12 (i.e., $45 \mathrm{kDa}$ ) fused with an $18 \mathrm{kDa}$ pET32b(+) vector, indicating the successful purification of GlaEst12 esterase. The esterase was purified for homogeneity with a $40 \%$ yield and a purification fold of 1.72 . The size of protein GlaEst12 was compared with the protein marker. Unlike with other HSL esterases, 
the molecular mass of GlaEst12 is $45 \mathrm{kDa}$, which is slightly higher than the reported range of molecular mass between 30-40 kDa [24-26].

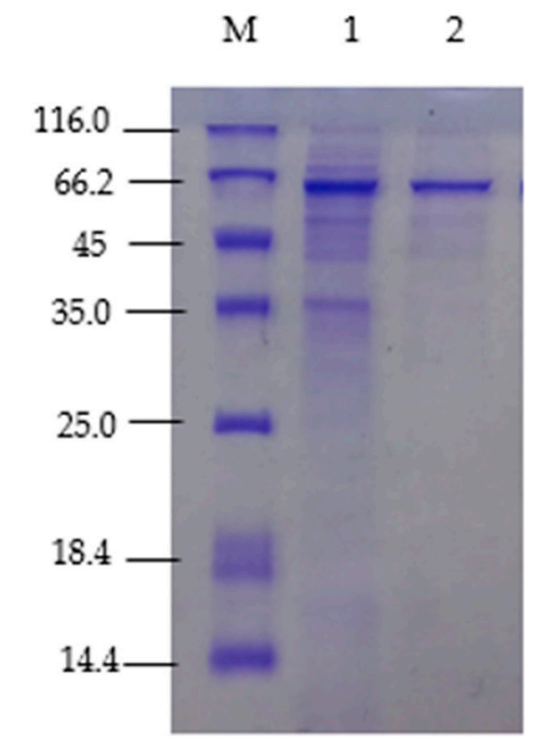

Figure 3. The SDS-PAGE analysis of purified GlaEst12 esterase. Lane M: unstained protein marker (Thermo Scientific, Waltham, MA, USA); Lane 1: refolded GlaEst12; Lane 2: purified GlaEst12-like esterase via Ni-Sepharose affinity chromatography.

\subsection{Characterisation of Purified GlaEst12}

\subsubsection{Effect of Temperature on GlaEst12 Esterase Activity and Stability}

The effect of temperature on GlaEst12 esterase activity and stability was studied by measuring the activity from $10-70{ }^{\circ} \mathrm{C}$ with an interval of $10^{\circ} \mathrm{C}$. Interestingly, the purified GlaEst12 has a broad temperature from $10-70{ }^{\circ} \mathrm{C}$ with an optimum temperature at $60^{\circ} \mathrm{C}$ (Figure $4 \mathrm{a}$ ) with $980 \mathrm{U} / \mathrm{mL}$, and the activity of GlaEst 12 dropped drastically at $70{ }^{\circ} \mathrm{C}$. This indicated that GlaEst 12 esterase exhibits thermophilic characteristics rather than psychrophilic, in which most of the reported enzymes from psychrophilic organisms have activity at low temperature with an optimal temperature range between $0-30{ }^{\circ} \mathrm{C}$ [27]. However, this is not the first reported enzyme from a psychrophilic microorganism that has broad temperature because there are already reported microbes isolated from the cold environment that appeared to produce thermotolerant lipases, such as AMS3 lipase from Pseudomonas sp. [28] and lipase ZJB09193 from Candida antarctica [29]. Another explanation of why GlaEst12 is able to withstand at a higher temperature is because of the presence of three cysteines in the amino acid composition. The cysteine consists of a thiolate group in the side chain that will form a disulphide bond that increases the rigidity of the protein, which plays a role in thermostability [27]. Figure $4 \mathrm{~b}$ shows the thermostability of GlaEst12, which was tested by incubating the enzyme at $10-70{ }^{\circ} \mathrm{C}$ for $30 \mathrm{~min}$. The results showed GlaEst 12 was most stable at $50{ }^{\circ} \mathrm{C}$ and when incubated at a lower temperature range from $10-40{ }^{\circ} \mathrm{C}$, the reduction of enzyme activity less than $40 \%$. Thermal stability is one of the important criteria for making an enzyme to be used for industrial purposes [30]. Esterases or lipases that have optimal activity at low or high temperatures make them a versatile biocatalyst [31]. 


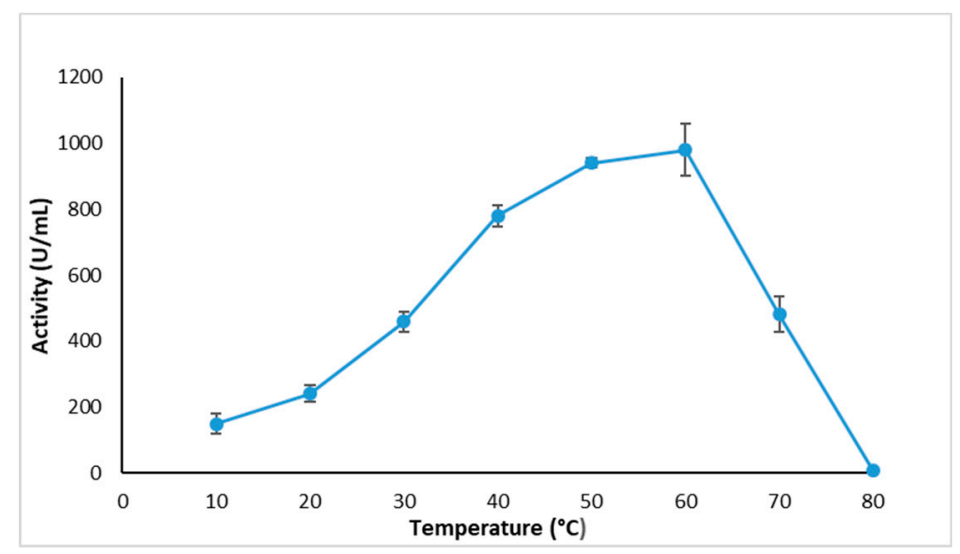

(a)

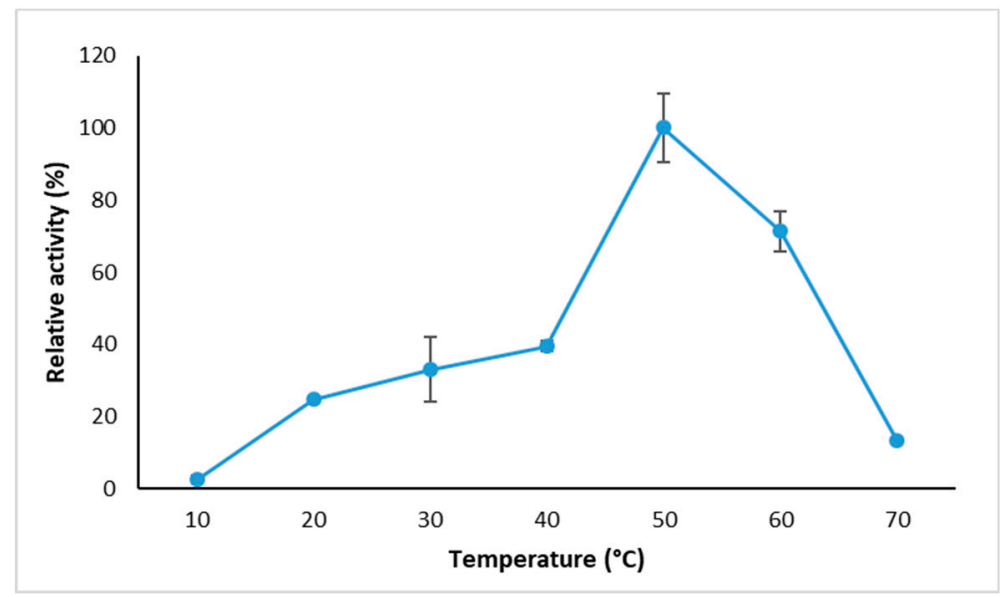

(b)

Figure 4. Effect of temperature on enzyme (a) activity and (b) stability of purified GlaEst12. The optimal temperature was determined by measuring the enzymatic activity at different temperatures ranged from $10-70{ }^{\circ} \mathrm{C}$ by using $\mathrm{C} 10$ as a substrate. The maximum optimal activity was observed at $60{ }^{\circ} \mathrm{C}$. The temperature stability of purified esterase was determined by measuring the residual activities after the enzyme had been incubated for $30 \mathrm{~min}$ at different temperatures $\left(10-80{ }^{\circ} \mathrm{C}\right)$ and the assay was performed at optimum temperature. Error bar represents standard deviation $(n=3)$. The absence of the bar indicates the error smaller than symbols.

\subsubsection{Effects of $\mathrm{pH}$ on GlaEst12 Activity and Stability}

The effect of $\mathrm{pH}$ on purified GlaEst12 esterase was tested on the different buffers with different $\mathrm{pH}$ ranging from $4-11$. This esterase showed maximum activity at $\mathrm{pH} 8$ using the Tris- $\mathrm{HCl}$ buffer. The GlaEst 12 tended to be stable at a $\mathrm{pH}$ ranging from 7 to 9 . Figure $5 \mathrm{a}$ shows the increasing trends of enzyme activity from $\mathrm{pH} 6$ of sodium acetate to $\mathrm{pH} 7$ and 8 of sodium phosphate, which peaked at $\mathrm{pH} 8$ of Tris- $\mathrm{HCl}$ and then decreased gradually from $\mathrm{pH} 9$ of Tris- $\mathrm{HCl}$ to $\mathrm{pH} 9-10$ of Glycine-OH. Extreme acidic and alkaline buffers (i.e., $\mathrm{pH}$ less than 6 and $\mathrm{pH}$ more than 10, respectively) exhibited unfavourable conditions for this esterase with enzyme activity less than $100 \mathrm{U} / \mathrm{mL}$. The $\mathrm{pH}$ stability of GlaEst12 was studied by treating the enzyme with various buffers for $30 \mathrm{~min}$. Then, the residual activity after incubation was measured, and the highest activity was denoted as $100 \%$ relative activity, as shown in Figure 5b. The $\mathrm{pH}$ stability shows a similar pattern to the effects of $\mathrm{pH}$ on the enzyme activity since the GlaEst12 esterase showed the most stable in Tris- $\mathrm{HCl} \mathrm{pH} 8$ and more than $50 \%$ of residual activity stable at $\mathrm{pH} 7-9$. Moreover, the result showed similar findings as reported in the other hormone-sensitive lipases, such as from Psychrobacter sp. TA144 and R. miehei, which have higher 
activity and tend to be stable at $\mathrm{pH} 8[11,20]$. The buffer with $\mathrm{pH}$ range between $4-6$ showed less than $10 \%$ enzyme activity, suggesting that the extreme acidic condition may affect the secondary structures, which ultimately leads to the reduction of the esterase activity.

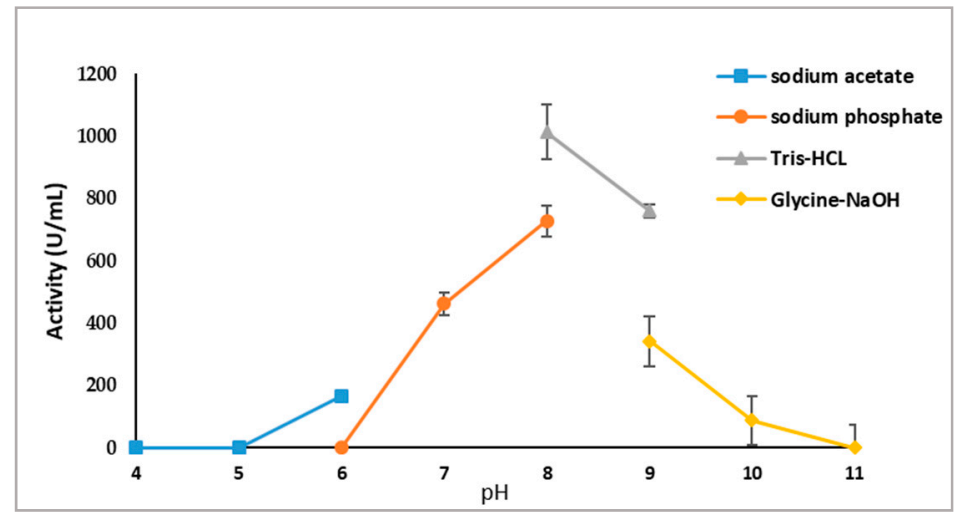

(a)

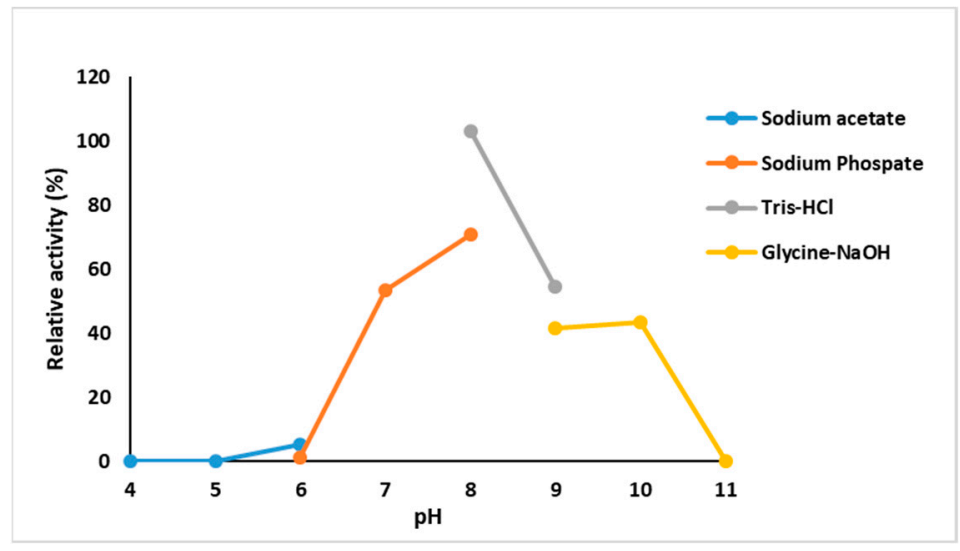

(b)

Figure 5. Effect of purified GlaEst12 esterase on enzyme (a) activity and (b) stability. The optimal $\mathrm{pH}$ was determined by measuring enzyme activity using $\mathrm{pNP}(\mathrm{C} 10)$ as a substrate in different buffer systems ranging from $\mathrm{pH} 4-11$. The $\mathrm{pH}$ stability was determined by incubating an enzyme at different buffers for $30 \mathrm{~min}$ and measuring the residual activity at optimum $\mathrm{pH}$. The buffer systems were used: sodium acetate ( $\mathrm{pH} 4-6$ ) (blue, filled square); sodium phosphate ( $\mathrm{pH}$ 6-8) (orange, filled circle); Tris-HCl ( $\mathrm{pH}$ 8-9) (grey, filled triangle), and glycine-OH ( $\mathrm{pH}$ 9-11) (yellow, filled diamond). Error bar represents standard deviation $(n=3)$. The absence of the bar indicates the error smaller than symbols.

\subsubsection{Substrate Specificity of GlaEst12 Esterase}

The study on the substrate specificity of GlaEst12 was examined using various $p$-nitrophenyl (pNP) esters with an acyl chain length from C2-C16 using standard assay. The esterase showed high substrate specificity toward middle chain esters, pNP decanoate rather than a shorter or a longer chain of pNP ester. Figure 6 shows that more than $80 \%$ of activity was achieved when GlaEst 12 used C 8 as a substrate, while about $50 \%$ activity dropped when this esterase was assayed with a longer chain that is more than 10 carbons. The shorter chain of carbon, such as $\mathrm{C} 2$ and C4, had the lowest activity, which was less than $10 \%$, indicating that the GLA has a low specificity toward the shorter carbon chain. The results showed differently from other esterases, for example, HSL esterase that has a protein sequence similarity with GlaEst12, E40 had the highest activity toward pNP butyrate (C4) [32], RmEstA from $R$. miehei prefers pNP hexanoate (C5) [24] and Est22 from deep-sea metagenomic library has the highest activity on pNP butyrate [33]. 


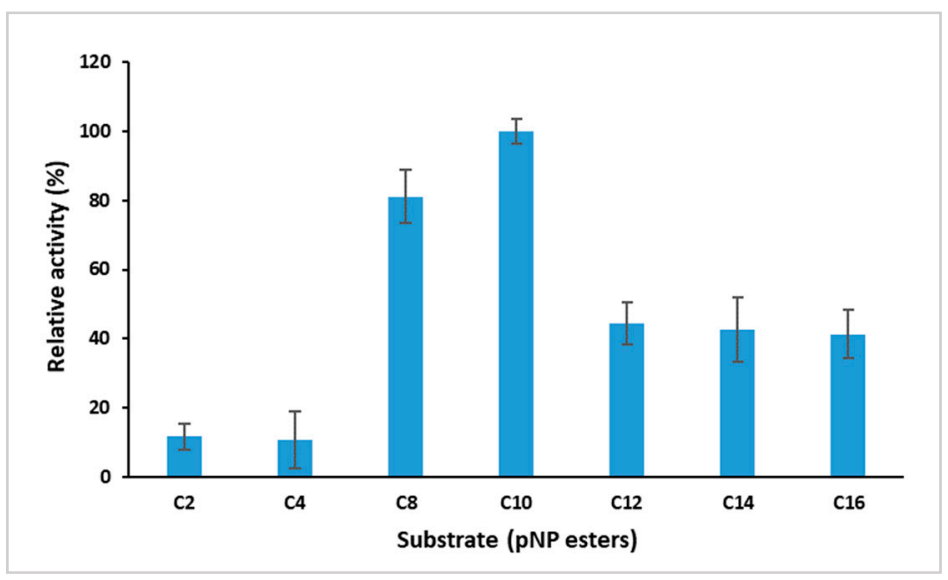

Figure 6. Effect of different pNP esters on purified GlaEst12 esterase. The activity of esterase was measured using different $\mathrm{pNP}$ esters at $60^{\circ} \mathrm{C}$ using $50 \mathrm{mM}$ Tris- $\mathrm{HCl} \mathrm{pH}$. The highest activity with p-nitrophenol decanoate (C10) substrate is shown as 100\%. Error bar represents standard deviation $(n=3)$.

\subsubsection{Effect of Metal Ions on Esterase Activity}

The importance of metal ions in enzyme catalysis is well established since there are many reported metal-dependent enzymes that enhanced enzyme activity. Each metal ion has different roles since they may play an important role in a redox reaction, stabilisation of negative charges, and activation of substrates by virtue of their Lewis acid properties [34]. Effect of metal ions on GlaEst12-like esterase was conducted by treating the enzyme with various metals ions at the concentration of $1 \mathrm{mM}$ and $5 \mathrm{mM}$. Figure 7 shows that metal ions $\left(\mathrm{Na}^{+}, \mathrm{K}^{+}, \mathrm{Ca}^{2+}\right.$, and $\mathrm{Mn}^{2+}$ ) enhanced the activity, which was higher than that in the control (enzyme without metal ions). However, $1 \mathrm{mM}$ and $5 \mathrm{mM}$ of $\mathrm{Mg}^{2+}$, $\mathrm{Ni}^{2+}$, and $\mathrm{Cu}^{2+}$ decreased and abolished the GlaEst12 esterase activity. For $\mathrm{Rb}^{+}$, lower concentration showed an increase in the enzyme activity, but the high concentration of $\mathrm{Rb}^{+}$had a negative effect on the enzyme activity. Most of the experiments that involved the HSL-like esterases showed that $\mathrm{Ni}^{2+}$ and $\mathrm{Cu}^{2+}$ tended to decrease the enzyme activity, such as EstAG1 from Staphylococcus saprophyticus and RmEsT from R. miehei [11,35].

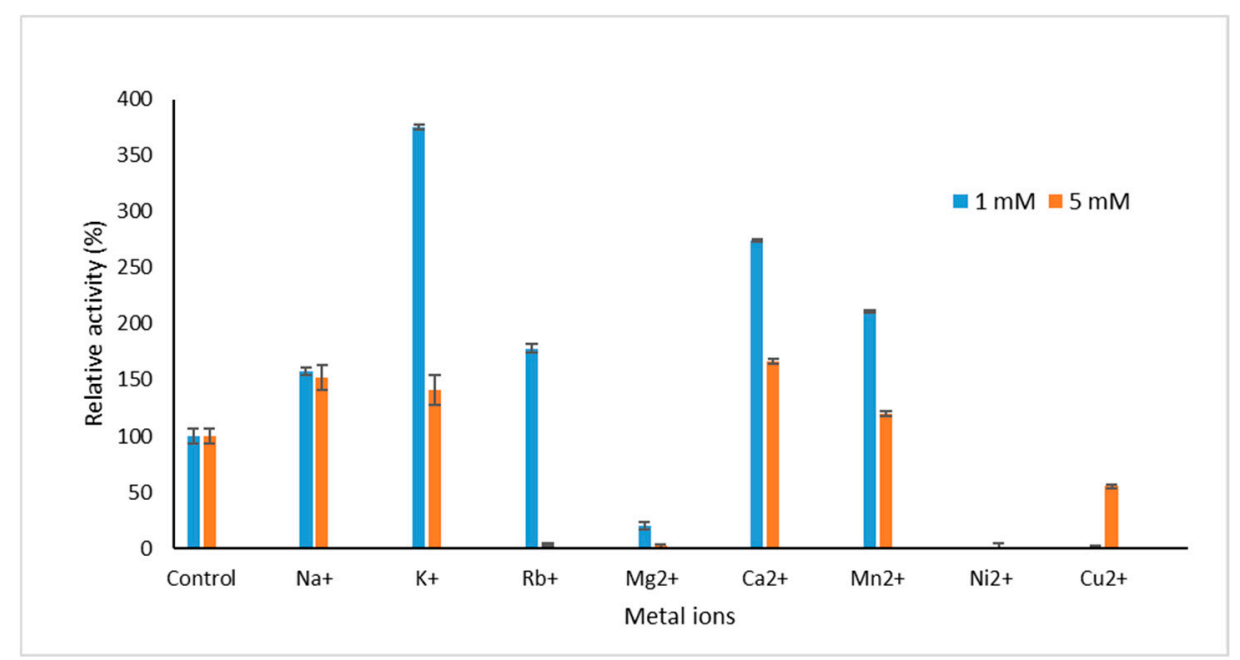

Figure 7. Effect of metal ions on the activity of purified GlaEst12-like esterase. The relative activity of the unincubated enzyme without metal ions (control) was taken $100 \%$. Error bar represents standard deviation $(n=3)$. 


\subsubsection{Effect of Organic Solvents on GlaEst12}

The stability of GlaEst12 esterase on organic solvents was studied by incubating the enzyme with polar and non-polar organic solvents based on log P-value. Figure 8 reveals the activity of GlaEst12 that is increasing with dimethyl sulfoxide (DMSO) (104\%), 1-propanol (123\%), and Toluene (113\%) compared to the control. However, other solvents such as methanol, acetonitrile, benzene, octanol, xylene, and $n$-hexane caused instability in the protein. Among organic solvents, DMSO tends to give better stability to the GlaEst12 and other HSL esterases, consistent with many previous studies that have reported that this solvent is able to enhance lipolytic activities, such as RmEstB esterase from R. miehei, rEst1 from Rheinheimera sp., and EstAG1 from S. saprophyticus $[11,35,36]$. Based on these results, the enzyme showed less tolerance to the organic solvents since they were unable to resist the denaturation by the organic solvent, and the presence of these solvents may prevent accessibility of substrate to the active site [37].

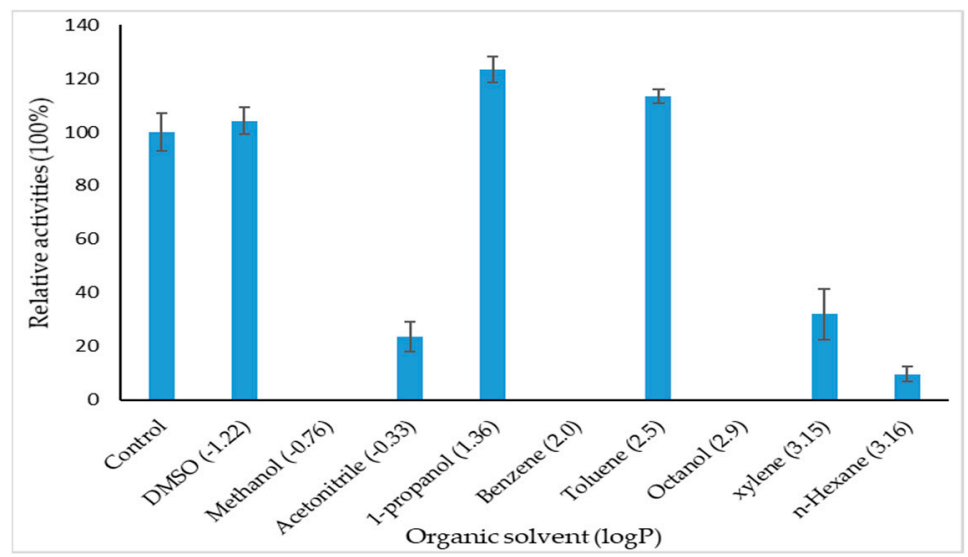

Figure 8. Effect of various organic solvents on the activity of purified GlaEst12-like esterase. The relative activity of the unincubated enzyme without organic solvent (control) was taken $100 \%$. The log $\mathrm{P}$ is the logarithm of the partition coefficient, $\mathrm{P}$, of the solvent between n-octanol and water, and is used as a quantitative measure of the polarity. Error bar represents standard deviation $(n=3)$.

\subsection{Homology Modelling and Validation of GlaEst12}

The homology modelling of GlaEst12 was done using the Robetta server (http://robetta.bakerlab. org/). The software uses two approaches to predict the structure, namely, comparative modelling or de novo structure prediction method. The de novo method was used when the query sequence was not matched with the template sequence and is known as the de novo Rosetta fragment insertion method [38]. Based on the multiple sequence alignments result, a crystal structure of Esterase 40 from the bacterial HSL family was chosen as the template to generate a 3D structure of GlaEst12 because it gave a higher score of sequence identity (about 30\%), and the structure E40 was already solved using X-ray diffraction method [32]. Figure 9a shows the predicted model of this esterase that exists as a dimer comprised of two monomers of the subunits. Each monomer is dominated by $33.08 \%$ of $\alpha$-helix followed by $9.52 \%$ and $57.39 \%$ of $\beta$-sheets and others, respectively. A higher number of $\alpha$-helix present in the structure might be helping the survival of this enzyme in the Antarctica environment because an increase in the number of $\alpha$-helix in protein structure tends to make the enzyme more flexible, which is responsible for enzyme activity at low temperatures [39]. The active site of GlaEst12-like esterase was predicted to be at position Ser 232, Glu 341, and His 371 (Figure 9b), which plays an important role in allowing the accessibility of the substrate. Serine residue located at the active site acts as a nucleophile, which is responsible for attacking the carbonyl group of the substrate, and this reaction later forms a tetrahedral intermediate together with the substrates, i.e., histidine and glutamate. In contrast with other esterases and lipases, mammalian HSL and the HSL-like esterase group exhibited conserved motif HGGG sequences. This sequence usually forms a loop in the secondary structure that is located 
in close proximity to the active site and contributes to the formation and stabilisation of the oxyanion hole [40].

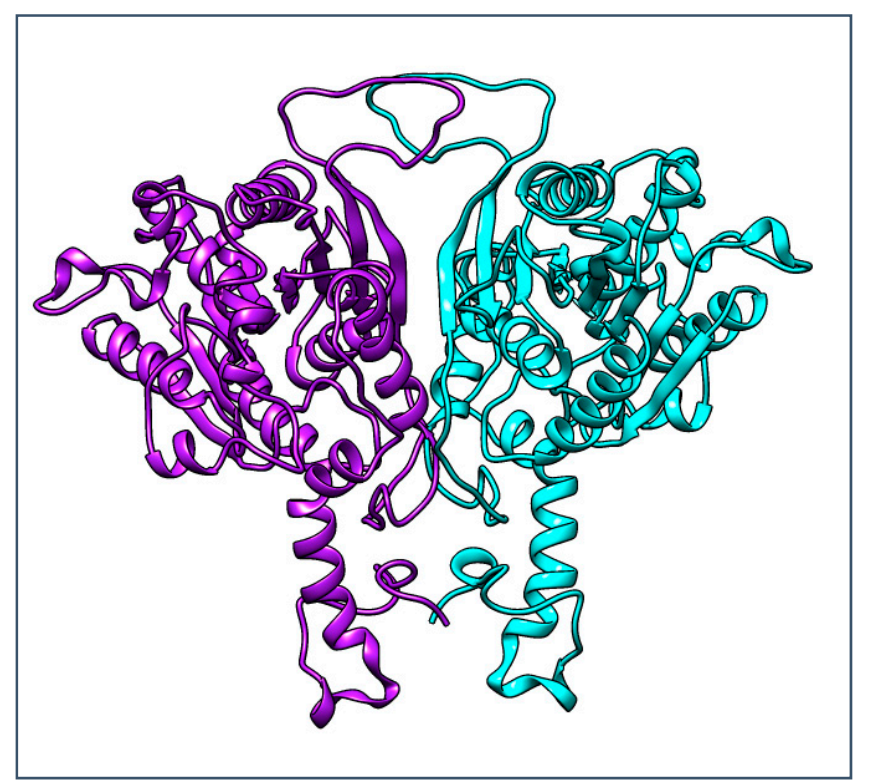

(a)

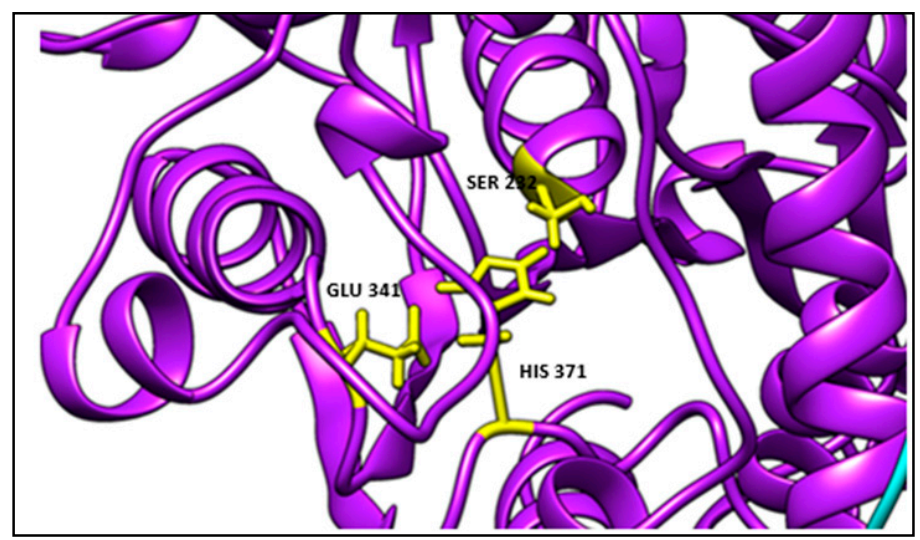

(b)

Figure 9. (a) The predicted GlaEst12 exists as dimer composed of two chain A (purple) and B (cyan) of $\alpha$-helix structure, $\beta$-sheet, and coiled structures. (b) The catalytic triad of GlaEst12 was positioned at $\mathrm{Ser}^{232}, \mathrm{Glu}^{341}$, and $\mathrm{His}^{371}$ and depicted in yellow.

The assessment of protein models with 3D profiles was performed using online websites with the predicted structure of HSL esterase as a subject (Table 1). VERIFY 3D was used to determine the accuracy of the atomic model (3D), where the result was generated by comparing the subject with the structures that had already been solved by crystallography or the nuclear magnetic resonance (NMR) method. From the results, it showed that GlaEst12 has $87.8 \%$ residues of amino acid that scored equal and above 0.2 in Verify 3D. Although the value of score was lower than $90 \%$, this structure is accepted because the residues have low scores at the N-terminal region, and the GLA esterase sequence is mostly conserved only at the central region as revealed by the multiple sequence alignment (Figure 1). This result showed consistency with the previous study, which stated that HSL lipase from the psychrophilic Psychrobacter sp. has sequence similarity with other homologous HSL proteins at the central region to the catalytic region. However, this psychrophilic enzyme has an additional sequence at the N-terminal region, which is expected to be the additional domain unique to the cold-adapted protein [20]. The addition of four $\alpha$-helix domains at the N-terminal in GlaEst12 comparing to the other HSLs might 
support the facts of the additional domain in HSL lipase from Psychrobacter since both of them are from the psychrophilic Antarctic. Besides that, the Errat tool was used to determine the accuracy and exactness of the atom distribution in the protein region and GlaEst12 has a high score that is more than $90 \%$. The predicted structure was validated using a Ramachandran plot and revealed that $84.8 \%$ of it, which is about 328 residues, was located at the favoured region, while the remaining $14.8 \%, 0.3 \%$, and $0.1 \%$ located at allowed, general, and outlier, respectively. The residues located at the disallowed region contributed about $0.1 \%$ of the total residues together with one of the catalytic triad, which is serine at position 232. The presence of the catalytic triad serine at negative region suggested that the enzyme is an active conformation. In contrast, the predicted structure of AMS8 lipase revealed that the catalytic serine is located at the allowed region and the protein is a closed conformation since it has the lid structure that covers the active site [41].

Table 1. The summary score for the predicted structure of GlaEst12 esterase using online web tools.

\begin{tabular}{llc}
\hline \multicolumn{1}{c}{ Validation Tools } & Score (\%) \\
\hline (A) & Verify 3D & 87.8 \\
(B) & Errat & 91.3 \\
(C) & Ramachandran Plot & \\
& Most favoured region & 84.8 \\
& Additional allowed region & 14.8 \\
& Generously allowed region & 0.3 \\
& Disallowed region & 0.1 \\
\hline
\end{tabular}

\section{Materials and Methods}

\subsection{Sequence Analysis of GlaEst12}

Previously, a psychrophilic yeast named G. antarctica was successfully isolated from sea ice near Casey Research Station, Antarctica. The whole-genome sequencing of this organism was done using 454 pyrosequencing and Illumina technology, with the protein information of $G$. antarctica being deposited in the Glaciozyma antarctica Genome Database (GanDB) (www.mgi-nibm.my/glaciozyma_ antarctica) [42]. The gene encoding for putative esterase was chosen and known as Glaciozyma antarctica hormone-sensitive lipase (GlaEst12) esterase. The protein sequence of GlaEst12 was analysed using the GenBank database BLASTp (http://www.ncbi.nih.gov) from the NCBI to search the protein similarity with the other proteins. The amino acid composition, molecular weight, and predicted pI value of GlaEst12 were determined using Expasy Tools (https://web.expasy.org/protparam/). The presence of the signal peptide was predicted using the online tool SignalP-5.0 server (http: //www.cbs.dtu.dk/services/SignalP/). The sequences similarity and secondary structure information from aligned sequences were performed using ENDscript 2.0 (http://endscript.ibcp.fr). The phylogenetic tree was constructed using MEGA 7.0, whereby the GlasEst12 protein was aligned with eight additional proteins (accession numbers: WP_012330536.1, ADH59412, QBH67630.1, KX580963.1, 4WY8, 4WY5, $4 \mathrm{QO} 5$, and 4Q30). The alignment was generated using Clustal $\mathrm{W}$, and the evolutionary history was inferred by using the Neighbour Joining method with a Jones-Taylor-Thornton (JTT) method.

\subsection{Gene Synthesis, Bacteria Strains, and Plasmids}

The sequence of GlaEst12-like esterase that encoded for 1200 nucleotides was sent for gene synthesis. Codon optimisation was performed based on preferred codons by E. coli to enhance GLA HSL lipase expression in the E. coli host system. This codon-optimised gene was synthesised together with restriction endonuclease EcoR1 and Xho1 placed at the beginning and at the end of the gene sequence (Integrated DNA Technologies, Coralville, IA, USA). This gene was also cloned into a cloning vector (pUCIDT) and supplied in the dried plasmids. Since the pUCIDT/GLA HSL plasmid was in the form of powder, plasmid resuspension was carried out according to the manufacturer's protocol (Integrated DNA Technologies, Coralville, IA, USA). For cloning and expression of the protein, pET32b 
(Merck, Kenilworth, NJ, USA) was used together with E. coli BL21(De3) as vector and expression host, respectively.

\subsection{Cloning of GlaEst12 in E. coli}

The gene that encoded GLA HSL lipase gene was amplified by PCR using recombinant plasmid pUCIDT/GLA HSL as a template. A set of forward and reverse primers with EcoRI and XhoI restriction sites were designed based on an optimised GLA HSL esterase gene sequence. The forward and reverse sequences are 5'CGTGAATTCGATGTTGAGTCCTG-3' and 5'GAGCTCTTAAAACTTCCCGTCTA-3', respectively, in which the underlined nucleotide sequences represent the sequences of EcoRI and XhoI. The PCR product was purified using a Gel Extraction kit (GeneAll, Seoul, Korea) and then digested with restriction enzymes EcoRI and XhoI. The digested PCR product was cloned into a pET32b vector (Merck, Kenilworth, NJ, USA) and transformed into E. coli BL21(De3) in tributyrin-containing ampicillin agar plates. The agar plates were incubated at $37^{\circ} \mathrm{C}$ for $16 \mathrm{~h}$ and followed by incubation at $4{ }^{\circ} \mathrm{C}$ for $24 \mathrm{~h}$. The positively transformed colonies were indicated by the formation of halo zones of colonies in tributyrin agar supplemented with ampicillin.

\subsection{Expression, Solubilisation, and Refolding of GlaEst12 Inclusion Bodies}

The recombinant GlaEst12 was expressed using pET32(b) + vector and transformed into E. coli BL21(De3). The expression was induced using $10 \mu \mathrm{M}$ IPTG at $16^{\circ} \mathrm{C}$ for $20 \mathrm{~h}$. Solubilisation of GlaEst12 was conducted as the enzyme was mostly expressed as inclusion bodies. The E. coli cell was harvested by centrifugation at $10,000 \times g$ for $15 \mathrm{~min}$. Then, the supernatant was discarded, and the pellet was resuspended with $20 \mathrm{~mL}$ of $50 \mathrm{mM}$ Tris- $\mathrm{HCl}(\mathrm{pH}$ 8) and subjected to sonication for 6 min under the output of 2 and duty cycle of 20 (Sonifer ${ }^{\circledR}$ SLP150 Branson, Danbury, CT, USA). The clear lysate was centrifuged at $10,000 \times g$ for $15 \mathrm{~min}$, and the pellet-containing insoluble protein was further resuspended with Tris- $\mathrm{HCl}$ buffer $(\mathrm{pH}$ 8) containing $8 \mathrm{M}$ of urea. The resuspend mixture was then incubated at $4{ }^{\circ} \mathrm{C}$ for $4 \mathrm{~h}$ with constant agitation. After incubation, the mixture was centrifuged with the same condition stated above, and the supernatant was used for further reaction. Renaturation of the supernatant containing the GlaEst12-like esterase was achieved by a 10× dilution of the denaturant in $50 \mathrm{mM}$ Tris- $\mathrm{HCl}$ buffer ( $\mathrm{pH}$ 8). The solubilised protein was diluted in one-step with a peristaltic pump of the flow rate of $0.5 \mathrm{~mL} / \mathrm{min}$ and stirred thoroughly at $4{ }^{\circ} \mathrm{C}$. The refolded protein was then subjected to enzyme assay.

\subsection{Purification of Recombinant of GlaEst12-Like Esterase}

The His-tagged of recombinant GlaEst12 was purified by single-step Ni-sepharose affinity chromatography. The filtered crude protein was loaded onto a Nickel-Sepharose HP column (XK16/20) (GE Healthcare, Boston, MA, USA). The binding buffer [ $20 \mathrm{mM}$ Sodium phosphate, $10 \mathrm{mM}$ imidazole, $500 \mathrm{mM} \mathrm{NaCl}$ (pH 7.4)] was used to equilibrate the column at a flow rate of $1 \mathrm{~mL} / \mathrm{min}$. Then, the crude protein was loaded onto the column, and the bound protein was eluted with an ascending step gradient of elution buffer [ $20 \mathrm{mM}$ Sodium phosphate, $500 \mathrm{mM}$ imidazole, $500 \mathrm{mM} \mathrm{NaCl}$ (pH 7.4)]. The eluted proteins were collected in $2 \mathrm{~mL}$ per fraction. The fractions containing the protein of interest were confirmed through pNP assay and SDS-PAGE. The fractions containing protein of interest were pooled, dialysed with buffer [ $50 \mathrm{mM}$ Tris- $\mathrm{HCl}, 50 \mathrm{mM} \mathrm{NaCl}(\mathrm{pH} 8)]$, and stored at $4{ }^{\circ} \mathrm{C}$ for further characterisation. The molecular weight of GlaEst12 was determined by using SDS-PAGE with $6 \%$ stacking gel and $12 \%$ separating gel, as described by Laemmli., 1970, with some modification [43]. The gel was stained using Coomassie Brilliant Blue R 250 (BioRad, Hercules, CA, USA) and destained with a destaining solution. The molecular mass of the protein was estimated using a broad range of protein standard markers (unstained protein marker 18.4-116 kDa, Thermo Scientific, Waltham, MA, USA). 


\subsection{Enzyme Assay}

A spectrophotometric method was used to determine the GlaEst12 activity using pNP substrate. The pNP released from the substrate was measured according to the method described by Sumby et al., 2009, with some modifications [44]. The mixture reaction consisted of $950 \mu \mathrm{L}$ of $50 \mathrm{mM}$ Tris- $\mathrm{HCl}(\mathrm{pH} 8)$, $25 \mu \mathrm{L}$ of $10 \mathrm{mM} p$-nitrophenyl decanoate (C10:0), and $25 \mu \mathrm{L}$ of $0.1 \mathrm{mg} / \mathrm{mL}$ enzyme. The mixture was assayed with shaking at $150 \mathrm{rpm}, 60^{\circ} \mathrm{C}$ for $10 \mathrm{~min}$. Then, the liberation of pNP was measured using Biochrom WPA UV/Visible spectrophotometer (Cambridge, UK) at $410 \mathrm{~nm}$. The absorbance of the sample was deduced with the control that the mixture stated above without the enzyme. One unit of esterase was defined as $1.0 \mu \mathrm{mol}$ of $\mathrm{pNP}$ released per min under the conditions stated above.

\subsection{Characterisation of Purified GlaEst12}

\subsubsection{Effect of Temperature on Activity and Stability}

The determination of the effective temperature of purified GlaEst12-like esterase on its activity was conducted by measuring the esterase activity (as mentioned in Section 3.6) assayed at different temperatures of $10-80{ }^{\circ} \mathrm{C}\left(10^{\circ} \mathrm{C}\right.$ interval $)$ for $10 \mathrm{~min}$. For thermostability, $25 \mu \mathrm{L}$ of the enzyme was first incubated with $50 \mathrm{mM}$ Tris- $\mathrm{HCl} \mathrm{pH} 8$ at different temperatures of $10-70{ }^{\circ} \mathrm{C}\left(10^{\circ} \mathrm{C}\right.$ interval) for $30 \mathrm{~min}$ without substrate. Then, the residual of enzyme activity was assayed together with $10 \mathrm{mM}$ p-nitrophenyl decanoate (C10) as substrate at the optimum temperature of $60^{\circ} \mathrm{C}$ for $10 \mathrm{~min}$.

\subsubsection{Effect of $\mathrm{pH}$ and $\mathrm{pH}$ Stability}

Different buffers were used to study and determine the optimum buffer for GlaEst12-like esterase under $\mathrm{pH}$ range from 4-11. The buffers used were $50 \mathrm{mM}$ sodium acetate $(\mathrm{pH} 4.0-6.0), 50 \mathrm{mM}$ sodium phosphate (pH 6.0-8.0), $50 \mathrm{mM}$ Tris- $\mathrm{HCl}$ (pH 8.0-9.0), and $50 \mathrm{mM}$ glycine- $\mathrm{NaOH}$ (pH 9.0-11.0). The $\mathrm{pH}$ stability was investigated by incubating the enzyme with different buffers as stated above at $60^{\circ} \mathrm{C}$ for $30 \mathrm{~min}$ and followed by enzyme assay (same as in point 3.6).

\subsubsection{Effect of Substrate Specificity}

The substrate specificity was determined by p-nitrophenyl esters with various chain lengths, including $p$-nitrophenyl acetate (C2), p-nitrophenyl butyrate (C4), p-nitrophenyl octanoate (C8), $p$-nitrophenyl decanoate (C10), p-nitrophenyl laurate (C12), p-nitrophenyl myristate (C14), and $p$-nitrophenyl palmitate (C16). The reaction mixtures containing $25 \mu \mathrm{L}$ of the purified enzyme, $950 \mu \mathrm{L}$ of $50 \mathrm{mM}$ Tris- $\mathrm{HCl} \mathrm{pH} \mathrm{8}$, and $10 \mathrm{mM}$ of different substrates were assayed at $60{ }^{\circ} \mathrm{C}$ for $10 \mathrm{~min}$.

\subsubsection{Effect of Metals Ions}

GlaEst12-like esterase was treated with $1 \mathrm{mM}$ and $5 \mathrm{mM}$ metal ions (i.e., $\mathrm{Li}^{+}, \mathrm{Na}^{+}, \mathrm{K}^{+}, \mathrm{Rb}^{2+}, \mathrm{Mg}^{2+}$, $\left.\mathrm{Ca}^{2+}, \mathrm{Mn}^{2+}, \mathrm{Ni}^{2+}, \mathrm{Cu}^{2+}\right)$. The treated enzyme was then subjected to enzyme assay. For $1 \mathrm{mM}$ of metal ions, $940 \mu \mathrm{L}$ of Tris- $\mathrm{HCl}$ buffer $\mathrm{pH} 8,25 \mu \mathrm{L}$ of the enzyme was treated with $10 \mu \mathrm{L}$ of metal ions for $30 \mathrm{~min}$ at $60^{\circ} \mathrm{C}$. Then, $25 \mu \mathrm{L}$ of $10 \mathrm{mM}$-nitrophenyl decanoate (C10) was added to the mixture and assay, as mentioned in point 3.6. For $5 \mathrm{mM}$, all the composition are same as $1 \mathrm{mM}$ except for the composition of buffer and metal ions, which used $900 \mu \mathrm{L}$ and $50 \mu \mathrm{L}$, respectively. The stability was determined as the relative activity to the control (i.e., without a metal ion).

\subsubsection{Effect of Organic Solvents}

The esterase was incubated for $30 \mathrm{~min}$ at $60^{\circ} \mathrm{C}$ with various organic solvents at a concentration of $25 \%(v / v)$. The solvents were selected based on their log P values (in parentheses): DMSO (-1.22), methanol (-0.76), acetonitrile (-0.33), 1-propanol (1.36) benzene (2.0), toluene (2.5), octanol (2.9), xylene (3.15), and $n$-hexane (3.16). The mixtures pre-incubate for $30 \mathrm{~min}$, which contained $700 \mu \mathrm{L}$ of $50 \mathrm{mM}$ of Tris- $\mathrm{HCl}(\mathrm{pH} 8), 25 \mu \mathrm{L}$ of the enzyme, and $250 \mu \mathrm{L}$ of organic solvents and later were assayed together 
with $10 \mathrm{mM}$ of $p$-nitrophenyl decanoate $(\mathrm{C} 10)$ at $60^{\circ} \mathrm{C}$. The stability was determined as the relative activity to the control (i.e., without organic solvent).

\subsection{Homology Modelling and Structure Validation}

The homology modelling was used to predict 3D structure using templates deposited in the Protein Data Bank (PDB) that have high similarity to GlaEst12. The 3D structure of GlaEst12 was generated by using the Robetta server (http://robetta.bakerlab.org) that provides automated tools for protein structure prediction, while the figures were prepared using the Chimera visual system (www.cgl.ucsf.edu/chimera). The validation of protein structure was done using online software such as Ramachandran Plot (http://www-cryst.bioc.cam.ac.uk/), Errat [45], and VERIFY 3D [46].

\section{Conclusions}

A novel HSL-like esterase family known as GlaEst12 is being introduced from G. antarctica, a psychrophilic yeast. Multiple sequence alignment with another hormone-sensitive lipase proteins revealed GlaEst12 as a new member of the GDSAG motif subfamily of the HSL family. GlaEst12-like esterase was successfully expressed in E. coli and purified with single-step nickel-sepharose affinity chromatography. Biochemical characterisation of this esterase showed interestingly higher activity and stability at a higher temperature, which gives a unique feature to HSL-like esterase that was isolated from psychrophilic yeast. Besides that, this esterase was activated when treated with metal ions $\left(\mathrm{Na}^{+}\right.$, $\mathrm{K}^{+}, \mathrm{Ca}^{2+} \mathrm{Mn}^{2+}$ ) and stabilised when incubated with 1-propanol and toluene. Homology modelling of this GlaEst12-like esterase showed the predicted structure of this enzyme that is composed of a typical $\alpha / \beta$ hydrolase fold with the catalytic residues found at $\operatorname{Ser}^{232}$, $\mathrm{Glu}^{341}$, and $\mathrm{His}^{371}$. The characterisation of GlaEst12 that can withstand a broad temperature and remain stable in an alkaline environment make it a potential catalyst in industrial application.

Author Contributions: Conceptualisation, H.M.T. and M.S.M.A.; methodology, H.M.T. and M.S.M.A.; validation, M.S.M.A., R.N.Z.R.A.R. and A.T.C.L.; formal analysis, H.M.T. and M.S.M.A.; investigation, H.M.T.; Resources, M.S.M.A., R.N.Z.R.A.R. and A.T.C.L.; data curation, H.M.T. and M.S.M.A.; writing (review and editing) H.M.T. and M.S.M.A.; visualisation, H.M.T., M.S.M.A. and R.N.Z.R.A.R.; supervision, M.S.M.A., R.N.Z.R.A.R., A.T.C.L.; project administration, M.S.M.A.; funding acquisition, M.S.M.A., R.N.Z.R.A.R. and A.T.C.L. All authors have read and agreed to the published version of the manuscript.

Funding: Putra Grant funded this research, grant number 9601600.

Acknowledgments: This research and H.M.T scholarship were supported by research grant (GP-IPS/2017/9601600) and Graduate Research Fellowship (GRF) fund from Universiti Putra Malaysia.

Conflicts of Interest: The authors declare no conflict of interest.

\section{References}

1. Jensen, M.B.V.; Horsfall, L.E.; Wardrope, C.; Togneri, P.D.; Marles-Wright, J.; Rosser, S.J. Characterisation of a New Family of Carboxyl Esterases with an OsmC Domain. PLoS ONE 2016, 11, e0166128. [CrossRef]

2. Fojan, P. What Distinguishes an Esterase from a Lipase: A Novel Structural Approach. Biochimie 2000, 82, 1033-1041. [CrossRef]

3. De Simone, G.; Mandrich, L.; Menchise, V.; Giordano, V.; Febbraio, F.; Rossi, M.; Pedone, C.; Manco, G. A Substrate-Induced Switch in the Reaction Mechanism of a Thermophilic Esterase: KINETIC EVIDENCES AND STRUCTURAL BASIS. J. Biol. Chem. 2004, 279, 6815-6823. [CrossRef]

4. Lampidonis, A.D.; Rogdakis, E.; Voutsinas, G.E.; Stravopodis, D.J. The Resurgence of Hormone-Sensitive Lipase (HSL) in Mammalian Lipolysis. Gene 2011, 477, 1-11. [CrossRef]

5. Langin, D.; Laurell, H.; Holst, L.S.; Belfrage, P.; Holm, C. Gene Organization and Primary Structure of Human Hormone-Sensitive Lipase: Possible Significance of a Sequence Homology with a Lipase of Moraxella TA144, an Antarctic Bacterium. Proc. Natl. Acad. Sci. USA 1993, 90, 4897-4901. [CrossRef]

6. Kim, T.D. Bacterial Hormone-Sensitive Lipases (BHSLs): Emerging Enzymes for Biotechnological Applications. J. Microbiol. Biotechnol. 2017, 27, 1907-1915. [CrossRef] 
7. Pöhlmann, C.; Wang, Y.; Humenik, M.; Heidenreich, B.; Gareis, M.; Sprinzl, M. Rapid, Specific and Sensitive Electrochemical Detection of Foodborne Bacteria. Biosens. Bioelectron. 2009, 24, 2766-2771. [CrossRef]

8. Febbraio, F.; Merone, L.; Cetrangolo, G.P.; Rossi, M.; Nucci, R.; Manco, G. Thermostable Esterase 2 from Alicyclobacillus acidocaldarius as Biosensor for the Detection of Organophosphate Pesticides. Anal. Chem. 2011, 83, 1530-1536. [CrossRef]

9. Jaeger, K.E.; Eggert, T. Lipases for Biotechnology. Curr. Opin. Biotechnol. 2002, 13, 390-397. [CrossRef]

10. Bassegoda, A.; Fillat, A.; Pastor, F.I.J.; Diaz, P. Special Rhodococcus sp. CR-53 Esterase Est4 Contains a GGG(A)X-Oxyanion Hole Conferring Activity for the Kinetic Resolution of Tertiary Alcohols. Appl. Microbiol. Biotechnol. 2013, 97, 8559-8568. [CrossRef]

11. Yan, Q.; Yang, S.; Duan, X.; Xu, H.; Liu, Y.; Jiang, Z. Characterization of a Novel Hormone-Sensitive Lipase Family Esterase from Rhizomucor miehei with Tertiary Alcohol Hydrolysis Activity. J. Mol. Catal. B Enzym. 2014, 109, 76-84. [CrossRef]

12. Petrovskaya, L.E.; Novototskaya-Vlasova, K.A.; Gapizov, S.S.; Spirina, E.V.; Durdenko, E.V.; Rivkina, E.M. New Member of the Hormone-Sensitive Lipase Family from the Permafrost Microbial Community. Bioengineered 2017, 8, 420-423. [CrossRef]

13. Li, P.Y.; Ji, P.; Li, C.Y.; Zhang, Y.; Wang, G.L.; Zhang, X.Y.; Xie, B.B.; Qin, Q.L.; Chen, X.L.; Zhou, B.C.; et al. Structural Basis for Dimerization and Catalysis of a Novel Esterase from the GTSAG Motif Subfamily of the Bacterial Hormone-Sensitive Lipase Family. J. Biol. Chem. 2014, 289, 19031-19041. [CrossRef]

14. Turchetti, B.; Thomas Hall, S.R.; Connell, L.B.; Branda, E.; Buzzini, P.; Theelen, B.; Müller, W.H.; Boekhout, T. Psychrophilic Yeasts from Antarctica and European Glaciers: Description of Glaciozyma Gen. Nov., Glaciozyma martinii sp. Nov. and Glaciozyma watsonii sp. Nov. Extremophiles 2011, 15, 573-586. [CrossRef]

15. Boo, S.Y.; Wong, C.M.V.L.; Rodrigues, K.F.; Najimudin, N.; Murad, A.M.A.; Mahadi, N.M. Thermal Stress Responses in Antarctic Yeast, Glaciozyma antarctica PI12, Characterized by Real-Time Quantitative PCR. Polar Biol. 2013, 36, 381-389. [CrossRef]

16. Alias, N.; Mazian, A.; Salleh, A.B.; Basri, M.; Rahman, R.N.Z.R. Molecular Cloning and Optimization for High Level Expression of Cold-Adapted Serine Protease from Antarctic Yeast Glaciozyma antarctica PI12. Enzym. Res. 2014, 2014,1-20. [CrossRef]

17. Hashim, N.H.F.; Sulaiman, S.; Abu Bakar, F.D.; Illias, R.M.; Kawahara, H.; Najimudin, N.; Mahadi, N.M.; Murad, A.M.A. Molecular Cloning, Expression and Characterisation of Afp4, an Antifreeze Protein from Glaciozyma antarctica. Polar Biol. 2014, 37, 1495-1505. [CrossRef]

18. Ramli, A.N.M.; Azhar, M.A.; Shamsir, M.S.; Rabu, A.; Murad, A.M.A.; Mahadi, N.M.; Illias, R.M. Sequence and Structural Investigation of a Novel Psychrophilic $\alpha$-Amylase from Glaciozyma antarctica PI12 for Cold-Adaptation Analysis. J. Mol. Model. 2013, 19, 3369-3383. [CrossRef]

19. Ramli, A.; Mahadi, N.; Rabu, A.; Murad, A.; Bakar, F.; Illias, R. Molecular Cloning, Expression and Biochemical Characterisation of a Cold-Adapted Novel Recombinant Chitinase from Glaciozyma antarctica PI12. Microb. Cell Fact. 2011, 10, 94. [CrossRef]

20. De Santi, C.; Tutino, M.L.; Mandrich, L.; Giuliani, M.; Parrilli, E.; Del Vecchio, P.; de Pascale, D. The Hormone-Sensitive Lipase from Psychrobacter sp. TA144: New Insight in the Structural/Functional Characterization. Biochimie 2010, 92, 949-957. [CrossRef]

21. Li, Z.; Su, L.; Wang, L.; Liu, Z.; Gu, Z.; Chen, J.; Wu, J. Novel Insight into the Secretory Expression of Recombinant Enzymes in Escherichia coli. Process Biochem. 2014, 49, 599-603. [CrossRef]

22. Deb, C. A Novel Lipase Belonging to the Hormone-Sensitive Lipase Family Induced under Starvation to Utilize Stored Triacylglycerol in Mycobacterium tuberculosis. J. Biol. Chem. 2006, 281, 3866-3875. [CrossRef] [PubMed]

23. Bornhorst, J.A.; Falke, J.J. Purification of Proteins Using Polyhistidine Affinity Tags. In Methods in Enzymology; Elsevier: Amsterdam, The Netherlands, 2000; Volume 326, pp. 245-254.

24. Liu, Y.; Xu, H.; Yan, Q.; Yang, S.; Duan, X.; Jiang, Z. Biochemical Characterization of a First Fungal Esterase from Rhizomucor miehei Showing High Efficiency of Ester Synthesis. PLoS ONE 2013, 8, e77856. [CrossRef]

25. Jeon, J.H.; Lee, H.S.; Kim, J.T.; Kim, S.J.; Choi, S.H.; Kang, S.G.; Lee, J.H. Identification of a New Subfamily of Salt-Tolerant Esterases from a Metagenomic Library of Tidal Flat Sediment. Appl. Microbiol. Biotechnol. 2012, 93, 623-631. [CrossRef] 
26. Jin, P.; Pei, X.; Du, P.; Yin, X.; Xiong, X.; Wu, H.; Zhou, X.; Wang, Q. Overexpression and Characterization of a New Organic Solvent-Tolerant Esterase Derived from Soil Metagenomic DNA. Bioresour. Technol. 2012, 116, 234-240. [CrossRef]

27. Salwoom, L.; Rahman, R.A.; Zaliha, R.N.; Salleh, A.B.; Convey, P.; Ali, M.; Shukuri, M. New Recombinant Cold-Adapted and Organic Solvent Tolerant Lipase from Psychrophilic Pseudomonas sp. LSK25, Isolated from Signy Island Antarctica. Int. J. Mol. Sci. 2019, 20, 1264. [CrossRef]

28. Latip, W.; Rahman, R.N.; Leow, A.T.; Shariff, F.M.; Ali, M.S. Expression and Characterization of Thermotolerant Lipase with Broad PH Profiles Isolated from an Antarctic Pseudomonas sp. Strain AMS3. PeerJ 2016, 4, e2420. [CrossRef]

29. Liu, Z.Q.; Zheng, X.B.; Zhang, S.P.; Zheng, Y.G. Cloning, Expression and Characterization of a Lipase Gene from the Candida antarctica ZJB09193 and Its Application in Biosynthesis of Vitamin A Esters. Microbiol. Res. 2012, 167, 452-460. [CrossRef]

30. Joseph, B.; Ramteke, P.W.; Thomas, G. Cold Active Microbial Lipases: Some Hot Issues and Recent Developments. Biotechnol. Adv. 2008, 26, 457-470. [CrossRef]

31. Lopez-Lopez, O.; Cerdan, M.; Siso, M. New Extremophilic Lipases and Esterases from Metagenomics. Curr. Protein Pept. Sci. 2014, 15, 445-455. [CrossRef]

32. Li, P.Y.; Chen, X.L.; Ji, P.; Li, C.Y.; Wang, P.; Zhang, Y.; Xie, B.B.; Qin, Q.L.; Su, H.N.; Zhou, B.C.; et al. Interdomain Hydrophobic Interactions Modulate the Thermostability of Microbial Esterases from the Hormone-Sensitive Lipase Family. J. Biol. Chem. 2015, 290, 11188-11198. [CrossRef] [PubMed]

33. Huang, J.; Huo, Y.Y.; Ji, R.; Kuang, S.; Ji, C.; Xu, X.W.; Li, J. Structural Insights of a Hormone Sensitive Lipase Homologue Est22. Sci. Rep. 2016, 6, 28550. [CrossRef] [PubMed]

34. Andreini, C.; Bertini, I.; Cavallaro, G.; Holliday, G.L.; Thornton, J.M. Metal Ions in Biological Catalysis: From Enzyme Databases to General Principles. J. Biol. Inorg. Chem. 2008, 13, 1205-1218. [CrossRef] [PubMed]

35. Gricajeva, A.; Bikutè, I.; Kalèdienè, L. Atypical Organic-Solvent Tolerant Bacterial Hormone Sensitive Lipase-like Homologue EstAG1 from Staphylococcus Saprophyticus AG1: Synthesis and Characterization. Int. J. Biol. Macromol. 2019, 130, 253-265. [CrossRef] [PubMed]

36. Virk, A.P. A New Esterase, Belonging to Hormone-Sensitive Lipase Family, Cloned from Rheinheimera sp. Isolated from Industrial Effluent. J. Microbiol. Biotechnol. 2011, 21, 667-674. [CrossRef] [PubMed]

37. Bansal, V.; Delgado, Y.; Fasoli, E.; Ferrer, A.; Griebenow, K.; Secundo, F.; Barletta, G.L. Effect of Prolonged Exposure to Organic Solvents on the Active Site Environment of Subtilisin Carlsberg. J. Mol. Catal. B Enzym. 2010, 64, 38-44. [CrossRef] [PubMed]

38. Kim, D.E.; Chivian, D.; Baker, D. Protein Structure Prediction and Analysis Using the Robetta Server. Nucleic Acids Res. 2004, 32, W526-W531. [CrossRef]

39. D'Amico, S.; Collins, T.; Marx, J.C.; Feller, G.; Gerday, C. Psychrophilic Microorganisms: Challenges for Life. EMBO Rep. 2006, 7, 385-389. [CrossRef]

40. Rehdorf, J.; Behrens, G.A.; Nguyen, G.S.; Kourist, R.; Bornscheuer, U.T. Pseudomonas Putida Esterase Contains a GGG(A)X-Motif Confering Activity for the Kinetic Resolution of Tertiary Alcohols. Appl. Microbiol. Biotechnol. 2012, 93, 1119-1126. [CrossRef]

41. Ali, M.S.M.; Ganasen, M.; Rahman, R.N.Z.R.A.; Chor, A.L.T.; Salleh, A.B.; Basri, M. Cold-Adapted RTX Lipase from Antarctic Pseudomonas sp. Strain AMS8: Isolation, Molecular Modeling and Heterologous Expression. Protein J. 2013, 32, 317-325. [CrossRef]

42. Firdaus-Raih, M.; Hashim, N.H.F.; Bharudin, I.; Abu Bakar, M.F.; Huang, K.K.; Alias, H.; Lee, B.K.B.; Mat Isa, M.N.; Mat-Sharani, S.; Sulaiman, S.; et al. The Glaciozyma antarctica Genome Reveals an Array of Systems That Provide Sustained Responses towards Temperature Variations in a Persistently Cold Habitat. PLoS ONE 2018, 13, e0189947. [CrossRef] [PubMed]

43. Laemmli, U.K. Cleavage of Structural Proteins during the Assembly of the Head of Bacteriophage T4. Nature 1970, 227, 680-685. [CrossRef] [PubMed]

44. Sumby, K.M.; Matthews, A.H.; Grbin, P.R.; Jiranek, V. Cloning and Characterization of an Intracellular Esterase from the Wine-Associated Lactic Acid Bacterium Oenococcus oeni. Appl. Environ. Microbiol. 2009, 75, 6729-6735. [CrossRef] [PubMed] 
45. Colovos, C.; Yeates, T.O. Verification of Protein Structures: Patterns of Nonbonded Atomic Interactions. Protein Sci. 1993, 2, 1511-1519. [CrossRef] [PubMed]

46. Luthy, R.; Bowie, J.U.; Eisenberg, D. Assesment of Protein Models with 3 Dimensional Profile. Nature 1992, 356, 83-85. [CrossRef]

(c)

(C) 2020 by the authors. Licensee MDPI, Basel, Switzerland. This article is an open access article distributed under the terms and conditions of the Creative Commons Attribution (CC BY) license (http://creativecommons.org/licenses/by/4.0/). 